\title{
Identificação molecular e fenotípica de bactérias de solo rizosférico com tolerância ao fungicida Mancozeb, em Manaus, Estado do Amazonas, Brasil
}

Molecular and phenotypic identification of bacteria from rhizosphere soil with tolerance to Mancozeb fungicide in Manaus, Amazonas State, Brazil

Identificación molecular y fenotípica de bacterias de suelo rizosférico con tolerancia al fungicida Mancozeb, en Manaus, Estado de Amazonas, Brasil

\author{
Carolina Rebière \\ Universidade Federal do Amazonas, Manaus, Amazonas, Brasil
}

\begin{abstract}
RESUMO
A utilização de fungicidas na agricultura tem se intensificado, causando grande impacto nos solos e na biota em que eles se encontram. A presença desses compostos no solo vem acarretando modificações no comportamento dos microrganismos, que passaram a adquirir estratégias de sobrevivência à presença desses produtos. $\bigcirc$ Mancozeb é um fungicida do grupo dos carbamatos, cuja ação pelo contato inativa as enzimas essenciais dos fungos. Os objetivos deste trabalho foram: isolar bactérias de solo; caracterizar os isolados com ensaios bioquímicos e ferramentas moleculares; obter o crescimento dos isolados em meio mínimo acrescido do fungicida; e estabelecer uma coleção de bactérias com potencial de biorremediação. As bactérias foram isoladas a partir de técnicas de isolamento em dois meios de cultura diferentes: meio mínimo e meio Bushnell Haas acrescidos de 3,6 $\mathrm{gL}^{-1} \mathrm{de}$ Mancozeb. Realizou-se a identificação por meio da caracterização fenotípica, utilizando-se de ensaios bioquímicos para determinar o gênero e identificação molecular pelo emprego do sequenciamento da região $16 \mathrm{~S}$, com os iniciadores 1492R, 513F, os quais amplificam 1.000 pares de base. Os 11 isolados de bactérias foram identificados em quatro famílias, quatro gêneros e 11 espécies. A família Bacillaceae foi a mais representativa, com 81,81\% dos isolados. Esses ensaios permitiram verificar a tolerância das bactérias isoladas em concentrações superiores às usadas em campo para o controle de pragas. A coleção de microrganismos decorrentes da realização dessa pesquisa poderá servir para estudos futuros envolvendo a biodegradação de xenobióticos.
\end{abstract}

Palavras-chave: Fungicida Industrial; Microbiologia do Solo; RNA Ribossômico 16S; Técnicas de Tipagem Bacteriana.

\section{INTRODUÇÃO}

Grandes quantidades de agrotóxicos são utilizadas nas lavouras e, dentre eles, os fungicidas lideram o ranking de consumo. A utilização de fungicidas na agricultura tem se intensificado, causando grande impacto nos solos e na biota em que eles se encontram. Desde os anos 1960, os fungicidas provenientes dos ditiocarbamatos têm sido mundialmente aplicados nas plantações, devido ao seu amplo espectro de ação sobre vários microrganismos, abrangendo cerca de 400 patógenos ${ }^{1,2}$.

\footnotetext{
Correspondência / Correspondence / Correspondencia:

Carolina Rebière

Rua Bernardo Lenz, $n^{\circ} 114$. Bairro: Praia dos Anjos

CEP: 28930-000 Arraial do Cabo-Rio de Janeiro-Brasil

Tel.: +55 (22) 2622-1296 / (22) 98178-7478

E-mail:caluesol@hotmail.com
}

Dentre os agrotóxicos empregados, o fungicida Mancozeb é o mais utilizado ${ }^{3}$. O Mancozeb é um fungicida com ação de contato, atua na inativação das enzimas essenciais para $\circ$ crescimento e desenvolvimento dos fungos, sendo largamente utilizado nos sistemas agrícolas, nas culturas de arroz, café e couve.

O Mancozeb, de nome comercial Dithane* NT é um fungicida do grupo dos carbamatos, e atua de forma inespecífica nas membranas dos fungos, inibindo a ação proteica e enzimática ${ }^{4}$. A presença desses compostos no solo vem acarretando modificações no comportamento dos microrganismos, que passaram a adquirir estratégias de sobrevivência à presença desses produtos ${ }^{5}$. Inúmeras são as referências sobre a biodegradação de agrotóxicos por microrganismos, demonstrando que, devido ao alto potencial genético que apresentam, estes são capazes de degradar essas substâncias ao ponto de mineralizá-las. 
Diversos gêneros e espécies possuem a capacidade de degradar certos polventes como moléculas de xenobióticos, em diferentes ambientes, atuando sobre esses produtos especialmente em consórcio ${ }^{6}$. Com o intuito de encontrar bactérias que se proliferem em ambientes com a presença de agrotóxicos e sejam capazes de realizar a biorremediação deste meio, os objetivos deste trabalho foram: isolar bactérias de solo com histórico de aplicação do fungicida Mancozeb em lavoura de Allium fistulosum L.; identificar os isolados com ensaios bioquímicos e ferramentas moleculares; obter o crescimento dos isolados em meio mínimo acrescido do fungicida; estabelecer uma coleção de bactérias com potencial de biorremediação.

\section{MATERIAIS E MÉTODOS}

\section{OBTENÇÃO DAS AMOSTRAS}

As amostras foram coletadas no período da manhã, na região rizosférica da cultura de cebolinha (Allium fistulosum L.). Coletaram-se cinco subamostras, as quais foram homogeneizadas, para formar uma amostra composta. Esta foi acondicionada em saco plástico esterilizado devidamente identificada e armazenada a $-4^{\circ} \mathrm{C}$ no Laboratório de Genética da Faculdade de Ciências Agrárias no Campus da Universidade Federal do Amazonas.

\section{ISOLAMENTO BACTERIANO}

As bactérias foram isoladas em meios seletivos contendo agrotóxicos como única fonte de carbono. $\bigcirc$ fungicida utilizado foi o Mancozeb, de nome comercial

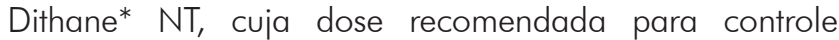
como fungicida nas lavouras, é de 2 a $3 \mathrm{~kg}$ por ha-1. Por essa razão pesou-se $200 \mathrm{~g}$ de solo rizosférico, mantido em incubadoras de 5,0 L com $3 \mathrm{~L}$ do meio Bushneel Haas $\mathrm{BH}$ : $\mathrm{MgSO}_{4} .7 \mathrm{H}_{2} \mathrm{O},(0,20 \mathrm{~g}) ; \mathrm{K}_{2} \mathrm{HPO}_{4}$ $(1,0 \mathrm{~g}) ; \mathrm{NH}_{4} \mathrm{NO}_{3}(1,0 \mathrm{~g}) ; \mathrm{FeCl}_{3} \cdot 6 \mathrm{H}_{2} \mathrm{O}(0,05 \mathrm{~g}) ; \mathrm{CaCl}_{2}^{4}$ $(0,02 \mathrm{~g})$ e o meio de cultivo quimiostático $\left(\mathrm{K}_{2} \mathrm{HPO}_{4^{\prime}}\right.$ 2,75 g; $\left(\mathrm{NH}_{4}\right)_{2} \mathrm{SO}_{4}, 1,0 \mathrm{~g} ; \mathrm{MgCl}^{2} \cdot 6 \mathrm{H}_{2} \mathrm{O}, 0,2 \mathrm{~g} ; \mathrm{NaCl}$, $0,1 \mathrm{~g} ; \mathrm{FeCl}_{3} \cdot 6 \mathrm{H}_{2} \mathrm{O}, 0,02 \mathrm{~g} ; \mathrm{CaCl}_{2}^{2}, 0,01 \mathrm{~g} ; \mathrm{H}_{2} \mathrm{O}$ destilada $999 \mathrm{~mL}$ mais $1 \mathrm{~mL}$ de elementos traços: $\mathrm{H}_{2} \mathrm{BO}_{3}$, $1,5.10^{-4} \%$; $\mathrm{MnSO}_{4}, 8,0.10^{-5} \%$; $\mathrm{ZnSO}_{4} .7 \mathrm{H}_{2} \mathrm{O}, 6,0.10^{-5 \%}$; $\mathrm{CuSO}_{4} .5 \mathrm{H}_{2} \mathrm{O}, 2,5.10^{-6} \%$; $\mathrm{CaSO}_{4} .7 \mathrm{H}_{2} \mathrm{O}, 1,0.10^{-7}$ ), tendo como única fonte de carbono o Dithane* NT a 3,6 $\mathrm{g} \mathrm{L}^{-1}$.

A incubação ocorreu a $28^{\circ} \mathrm{C}$ por sete dias. Após esse período, $100 \mathrm{~mL}$ do meio fermentado foi retirado e inoculado novamente em $3 \mathrm{~L}$ do mesmo meio anteriormente citado e incubado por mais sete dias nas mesmas condições de cultivo. Esse procedimento foi repetido por mais duas vezes, quando então ocorreu a diluição em série $\left(10^{-1}, 10^{-2}, 10^{-3}, 10^{-4}\right)$ do meio de cultivo da última fermentação e semeadura em placas de Petri em meio $\mathrm{BH}$ e quimiostático ${ }^{7}$. Para obtenção das culturas isoladas repicaram-se todas as colônias de microrganismos que se desenvolveram nas placas e fez-se a purificação pela técnica de esgotamento por estrias. Após terem sido purificadas, as mesmas foram devidamente identificadas e armazenadas em triplicata, em microtubos de $1 \mathrm{~mL}(310 \mu \mathrm{L}$ da cultura crescida em meio Luria-Bertani - LB - (triptona - $1 \mathrm{~g}$ de extrato de levedura - 0,5 g, $\mathrm{NaCl}-1 \mathrm{~g}$ ), e $690 \mu \mathrm{L}$ de glicerol $50 \%$, autoclavados e guardados a $-80^{\circ} \mathrm{C}$.

\section{Identificação fenotípica}

A identificação fenotípica das bactérias ocorreu submetendo os isolados bacterianos a 16 ensaios bioquímicos por meio dos quais verificaram-se as reações metabólicas dos microrganismos e as características morfológicas das colônias ${ }^{8}$. A partir dessas características, usou-se o Manual de Bergey's de Sistemática Bacteriológica ${ }^{9}$ e o Manual de Microbiologia Clínica para Controle de Infecções de Serviços de Saúde, da Agência Nacional de Vigilância Sanitária ${ }^{10}$, possibilitando identificar os isolados em nível de gênero.

Os 16 ensaios foram: método de coloração de Gram, verificação de enzimas de oxidase, catalase, ensaios de oxidação e fermentação, motilidade, produção de $\mathrm{H}_{2} \mathrm{~S}$, utilização de ureia e citrato, provas fermentativas com glicose, inositol, dulcitol, arabinose, ensaio de fermentação de lactose, hemólise e verificação de enzimas de $\alpha, \beta$-amilase e triptofanase. Em todos os ensaios os materiais utilizados, como placas de Petri, tubos, bem como os meios utilizados, foram devidamente autoclavados a $121^{\circ} \mathrm{C}$ por $20 \mathrm{~min}$. Os ensaios foram realizados em duplicata e incubados a $30^{\circ} \mathrm{C}$ por tempo de 18-24 h.

\section{Identificação genotípica}

A segunda parte da identificação foi a molecular, na qual se utilizou parte do gene 165 rRNA. A extração do DNA ocorreu pelo método do fenol/clorofórmio modificado"1. A amplificação do gene 165 rRNA foi realizada por meio da reação em cadeia de polimerase - PCR, com oligonucleotídeos iniciadores: 530 F (5'TGA CTG ACT GAG TGC CAG CMG CCG CGG-3') e 1492R (5'TGA CTG ACT GAG AGC TCT ACC TTG TTA ACM CGM CTT 3') que amplificam 1.000 pares de bases. A amplificação consistiu de um volume final de $25 \mu \mathrm{L}\left(\mathrm{MgCl}_{2} 50 \mathrm{mM}\right.$, DNTPs 2,5 mM, $5 \mathrm{pmol} / \mu \mathrm{L}$ de cada iniciador, 1,25 $\mathrm{U} / \mu \mathrm{L}$ de Platinum Taq DNA polimerase High Fidelity, tampão 10X, DNA bacteriano a uma concentração de 30-100 ng, completou-se com água Milli-Q)12. Foi utilizado como controle o DNA bacteriano da Escherichia coli ATCC 25922.

ciclo de amplificação consistiu no perfil térmico, que se iniciou com a desnaturação inicial a $95^{\circ} \mathrm{C}$ por 2 min, seguido por 35 ciclos de desnaturação de fitas-molde a $95^{\circ} \mathrm{C}$ por $40 \mathrm{~s}$; o pareamento dos iniciadores deu-se a $60^{\circ} \mathrm{C}$ por $40 \mathrm{~s}$ e a extensão a $72^{\circ} \mathrm{C}$ por $1 \mathrm{~min}$. $\bigcirc$ aparelho utilizado neste procedimento foi um termociclador. A reação de sequenciamento foi processada utilizando-se $2 \mu \mathrm{L}$ de DNA, purificado (50 ng), em seguida preparou-se o mix da reação: 0,3 $\mu \mathrm{L}$ de $\mathrm{AB}$ I Big Dye do kit de reação Big Dye Terminator Cycle Sequencing (Applied Biosystems, EUA) $2 \mu \mathrm{L}$ do primer 530F e 1492R concentração de $5 \mathrm{pmol} / \mu \mathrm{L} ; 2 \mu \mathrm{L}$ de tampão $5 \mathrm{X}$ e completou-se com água Milli-Q para um volume final de $10 \mu \mathrm{L}$. $\bigcirc$ perfil térmico consistiu de 25 ciclos, como segue: desnaturação de fitas-molde a $96^{\circ} \mathrm{C}$ por $10 \mathrm{~s}$, anelamento a $50^{\circ} \mathrm{C}$, com extensão a $60^{\circ} \mathrm{C}$ por 1 min e $20 \mathrm{~s}$.

$A$ reação de sequenciamento foi efetuada usando o kit BigDye Terminator v3.1 Cycle Sequencing Kit (Applied Biosystems, EUA), conforme protocolo do fabricante. 
A seguir, as sequências foram obtidas por eletroforese capilar em sequenciador ABI 3130 (Applied Biosystems, EUA).

A qualidade das sequências obtidas foi avaliada utilizando-se o programa Phred para remoção dos iniciadores, contaminantes e de nucleotídeos de baixa qualidade. As mesmas foram editadas utilizando o programa Bioedit versão 7.1.11 13. Cada sequência foi comparada com sequências depositadas no GenBank utilizando-se o programa de busca avançada Basic Local Alignment Search Tool (BLAST) do National Center of Biotechnology Information $(\mathrm{NCBI})^{14}$, utilizando-se os parâmetros nucleotide blast, others database set e highly similar sequences.

Para determinar a concentração inibitória mínima (CIM) de Mancozeb sobre as bactérias isoladas, os inóculos foram preparados em caldo mínimo M09 até a turbidez de uma solução padrão de Mac Farland de 0,5 $\left(2 \times 10^{8} \mathrm{UFC} / \mathrm{mL}\right)$ e transferidos $1 \mathrm{~mL}$ nas concentrações de $0,00011 \mathrm{mgL}^{-1}$ a $62,5 \mathrm{mgL}^{-1}$ de Manconzeb para tubos de ensaio de $10 \mathrm{~mL}$ de volume. Utilizou-se como controle Chromobacterium violaceum CVMO3. A leitura da CIM foi realizada após 18 h; ao ser determinada, realizou-se o plaqueamento, no mesmo meio, para verificar a ação bacteriostática do fungicida Mancozeb. A CIM, entretanto, não representa um valor absoluto, encontra-se na concentração do ensaio que inibe o crescimento do organismo (ou seja, a leitura da $\mathrm{CIM}^{15}$.

\section{RESULTADOS}

Foram isoladas 23 amostras bacterianas; destas 11 foram selecionadas de acordo com sua maior tolerância ao Mancozeb (Quadro 1), para serem realizadas as etapas de identificação. A partir das características fenotípicas observadas no quadro 2, utilizou-se o Manual de Bergeys ${ }^{9}$ para identificar os isolados em nível de gênero e espécie. Os isolados 14, 16, 18, 27, 39 e 42 foram identificados como Bacillus sphaericus utilizando-se a chave de Bacillus spp. Os isolados 1, 4 e 7 foram identificados como pertencentes ao gênero Bacillus.

isolado 22 foi identificado como Pseudomonas sp, utilizando a chave de identificação dos bastões gram negativos. $\bigcirc$ isolado 44 não foi possível ser identificado em nível de espécie a partir da utilização da chave da família Enterobacteriaceae, sendo identificado como Enterobacter sp.

No quadro 3 podemos observar a grande similaridade das sequencias de DNA dos isolados (\% cobertura) com as amostras do bancos de dados genéticos (genbank).

Quadro 1 - Concentração inibitória mínima dos isolados com resistência ao Mancozeb

\begin{tabular}{|c|c|c|c|}
\hline Isolado & Família & Espécie & CIM \\
\hline 1 & \multirow{9}{*}{ Bacillaceae } & $\begin{array}{l}\text { Lysinibacillus } \\
\text { sphaericus }\end{array}$ & $0,061 \mathrm{mg} \cdot \mathrm{L}-1$ \\
\hline 4 & & $\begin{array}{l}\text { Lysinibacillus } \\
\text { sphaericus }\end{array}$ & $0,244 \mathrm{mg} \cdot \mathrm{L}-1$ \\
\hline 7 & & $\begin{array}{l}\text { Lysinibacillus } \\
\text { sphaericus }\end{array}$ & $0,488 \mathrm{mg} \cdot \mathrm{L}-1$ \\
\hline 14 & & Bacillus sp. & $0,976 \mathrm{mg} \cdot \mathrm{L}-1$ \\
\hline 16 & & Bacillus pumillus & $0,244 \mathrm{mg} \cdot \mathrm{L}-1$ \\
\hline 18 & & $\begin{array}{c}\text { Lysinibacillus } \\
\text { sphaericus }\end{array}$ & $0,244 \mathrm{mg} \cdot \mathrm{L}-1$ \\
\hline 27 & & Bacillus sp. & $0,976 \mathrm{mg} \cdot \mathrm{L}-1$ \\
\hline 39 & & Bacillus altitudinis & $0,976 \mathrm{mg} \cdot \mathrm{L}-1$ \\
\hline 42 & & Bacillus aerophilus & $0,122 \mathrm{mg} \cdot \mathrm{L}-1$ \\
\hline 44 & Enterobactereaceae & Enterobacter sp. & $0,061 \mathrm{mg} \cdot \mathrm{L}-1$ \\
\hline 22 & Pseudomonadaceae & Pseudomonas sp. & $0,122 \mathrm{mg} \cdot \mathrm{L}-1$ \\
\hline
\end{tabular}

Quadro 2 - Características fenotípicas de 11 isolados com base na tolerância ao Mancozeb

\begin{tabular}{|c|c|c|c|c|c|c|c|c|c|c|c|}
\hline Isolados & 1 & 4 & 7 & 14 & 16 & 18 & 22 & 27 & 39 & 42 & 44 \\
\hline Forma & B & B & $B$ & B & B & B & B & $B$ & B & $B$ & C \\
\hline Gram & + & + & + & + & + & + & - & + & + & + & - \\
\hline Oxidase & + & + & + & + & + & + & + & - & - & + & + \\
\hline Catalase & + & + & + & + & + & + & + & + & + & + & + \\
\hline Oxidação & - & - & + & + & + & + & + & + & + & + & - \\
\hline Fermentação & + & + & + & + & + & + & + & + & + & + & + \\
\hline Motilidade & + & + & + & + & + & + & + & + & + & + & + \\
\hline $\mathrm{H}_{2} \mathrm{~S}$ & - & - & - & - & - & - & - & - & - & - & - \\
\hline Indol & - & - & - & - & - & - & - & - & - & - & - \\
\hline Urease & + & - & + & + & - & + & + & - & + & + & + \\
\hline Citrato & + & + & + & + & + & + & + & + & + & + & + \\
\hline Lactose & - & - & - & - & - & - & + & - & - & - & - \\
\hline Hemólise & $\alpha$ & - & $\beta$ & $\beta$ & - & A & $\alpha$ & $\alpha$ & - & - & - \\
\hline Arabinose & + & - & + & + & + & + & - & - & + & + & + \\
\hline Dulcitol & + & + & + & + & + & + & + & + & + & + & + \\
\hline Inositol & + & - & + & + & + & + & - & - & + & + & + \\
\hline Amilase & - & - & - & - & - & - & - & - & - & - & - \\
\hline
\end{tabular}

+: Positivo; -: Negativo; B: Bastão; C: Coco; $\alpha$ : Hemólise parcial; $\beta$ : Hemólise total; A: Hemólise nula. 
Quadro 3 - Identificação molecular de 11 isolados com base na tolerância ao Mancozeb

\begin{tabular}{|c|c|c|c|c|c|}
\hline Isolado & Família & Espécie & $\%$ Cobertura & $\%$ ID & Gen bank \\
\hline 1 & Bacillaceae & Lysinibacillus sphaericus & 100 & 94 & KC188670.1 \\
\hline 4 & Bacillaceae & Lysinibacillus sphaericus & 100 & 99 & KC188670.1 \\
\hline 7 & Bacillaceae & Lysinibacillus sphaericus & 100 & 99 & KC211310.1 \\
\hline 14 & Bacillaceae & Bacillus sp. & 95 & 93 & FR821104.1 \\
\hline 16 & Bacillaceae & Bacillus pumillus & 100 & 99 & NR074977.1 \\
\hline 18 & Bacillaceae & Lysinibacillus sphaericus & 100 & 99 & KC211310.1 \\
\hline 22 & Pseudomonadaceae & Pseudomonas sp. & 100 & 99 & JF293317.1 \\
\hline 27 & Bacillaceae & Bacillus sp. & 97 & 98 & $A B 126753.2$ \\
\hline 39 & Bacillaceae & Bacillus altitudinis & 100 & 99 & KC414719.1 \\
\hline 42 & Bacillaceae & Bacillus aerophilus & 100 & 99 & KC414720.1 \\
\hline 44 & Enterobacteriaceae & Enterobacter sp. & 100 & 99 & KC236536.1 \\
\hline
\end{tabular}

\section{DISCUSSÃO}

solo é um ambiente com uma vasta diversidade de microrganismos. No entanto, pouco conhecimento tem-se sobre essa diversidade, principalmente devido aos métodos tradicionais de isolamento e cultivo dos microrganismos ${ }^{16}$, cujos diferentes meios de cultura propostos para essas práticas têm elevado custo, são de preparo demorado, com ingredientes incomuns, além de alguns resultados serem obtidos após 14 dias. As bactérias representam a maior parte da população microbiana do solo, tanto em quantidade como em variedade; inúmeros são os gêneros e espécies encontrados. Neste trabalho, 81,81\% dos isolados foram identificados como Bacillus.

A identificação fenotípica dos Bacillus tem sido considerada complicada ${ }^{17}$, apesar das chaves propostas para essa identificação. Tal dificuldade ocorre por ter o gênero muitas características, e ser um grupo taxonômico grande, existindo grande variação de características entre linhagens. $\bigcirc$ gênero Bacillus é considerado um grupo altamente heterogêneo de bactérias Gram-positivas e negativas, o que gera muita complexidade em sua classificação taxonômica. Com recentes estudos da sistemática bacteriana, muitas espécies desse grupo foram reclassificadas, principalmente com uso do gene completo $16 \mathrm{~S}$ rRNA; porém, devido à elevada variabilidade genética, muitas espécies de Bacillus continuam sem classificação?. Um exemplo de reclassificação é o gênero Lysinibacillus, inicialmente nomeado como Bacillus, gênero este que foi criado para agrupar bactérias que apresentavam características distintas de outras espécies do grupo Bacillus, classificado por Ahmed et $a^{18}$. Por isso adotou-se, neste trabalho, a junção da identificação fenotípica com a molecular, com o intuito de facilitar esta identificação.
No que se refere à tolerância às drogas, esta é definida como a capacidade da bactéria mostrar-se sensível à CIM do xenobiótico, apresentando maior capacidade de sobreviver na presença deste. Ressalta-se, neste estudo, que os isolados com a mesma identificação em nível de gênero e espécie tiveram resultados de crescimento distintos para as mesmas concentrações do xenobiótico, inferindo que existe diversidade de tolerância para a mesma espécie, informação esta que vem ao encontro da heterogeneidade citada pelos taxonomistas acerca deste gênero.

Usaram-se, como parâmetro para análise de resistência ao xenobiótico, as concentrações aplicadas no campo de acordo com o bula do produto (Dithane* NT) 2 a $3 \mathrm{~kg} \mathrm{ha}{ }^{-1}$ ou $430 \mathrm{mg} \mathrm{L}^{-1}$. Dentre as bactérias identificadas, os isolados de Bacillus sp. (14), Bacillus sp. (27), B. altitudinis (39) apresentaram crescimento em concentrações superiores às utilizadas em campo, o que demonstra que estas apresentaram maior tolerância que as demais. Inúmeras são as espécies isoladas de solos com histórico de aplicação de herbicidas, fungicidas e/ou inseticidas. Esses microrganismos têm apresentado grande potencial de biorremediação para cada produto. Em decorrência desses estudos, diversos metabólitos têm sido produzidos, vários genes e proteínas envolvidos estão sendo conhecidos, aprofundando cada vez mais - conhecimento sobre a degradação e como essa atividade pode ser utilizada amenizando o impacto dos agrotóxicos sobre os solos e, consequentemente, sobre a saúde humana e dos animais.

Mandal Kousik et al ${ }^{19}$ isolaram diferentes espécies de Bacillus identificados como: Bacillus sp., B. mycoides, B. funiculus, B. marisflavi, B. weihenstephanensis, de solos contaminados com o finopril, em campos de produção de cana-de-açúcar. Este inseticida é utilizado no controle de vários insetos e pragas, e apresenta alta 
resistência no solo. Experimentos de biodegradação foram conduzidos no laboratório, no qual se analisou a dissipação do inseticida e seus metabólitos formados.

Scopel ${ }^{20}$ isolou do solo cepas com resistência ao glifosato. Este herbicida é intensamente utilizado no controle de plantas espontâneas, em diversas culturas. Bactérias foram isoladas de solos cultivados com macieira e crescidas em meios adicionados de $300 \mu \mathrm{gmL}^{-1}$, e foram identificadas como Pseudomonas sp., P. aeruginosa, Serratia sp., e Arthrobacter sp. A capacidade de degradar essa substância foi avaliada em 32 dias, atingindo um percentual de 99,8\% de degradação.

Sarkar et $a^{21}$ isolaram da rizosfera de plantio de chá (Camellia sinensis L.), linhagens de P. putida, as quais toleraram altas concentrações do acaricida propargite (10 $\left.\mathrm{mgL}^{-1}\right)$. Contudo, a degradação mostrou-se bastante superior quando o meio mineral utilizado no crescimento das linhagens foi acrescido de glicose. A degradação então atingiu 79,3\% em 24 h, para 32\% em meio mineral sem glicose no mesmo período.

Singh et al ${ }^{22}$ avaliaram, a partir de solos contaminados com malation, o percentual de degradação por Brevibacillus sp. e Bacillus cereus. Ambos os gêneros apresentaram altos percentuais de degradação, $72,20 \%$ e $87,40 \%$ respectivamente. Do mesmo modo Batisson et $a^{23}$ isolaram Bacillus sp. e Arthrobacter sp. capazes de degradar o mesotrione, um herbicida amplamente utilizado nas lavouras de milho.
As referências citadas corroboram a identificação dos isolados deste trabalho ao gênero Bacillus, os quais se destacam em ambientes contaminados, inclusive utilizando esses xenobióticos como fonte de nutrientes em seu metabolismo.

Por conseguinte, as abordagens fenotípica e molecular possibilitaram a identificação taxonômica de todos os 11 isolados. A partir dos resultados foram identificados três famílias, seis gêneros e oito espécies. As características fenotípicas observadas corroboraram os resultados obtidos pela análise de sequências do gene 16S rRNA. A família Bacillaceae foi a mais representativa neste estudo; todas as famílias e os gêneros identificados possuem referências com biodegradação de pesticidas.

\section{CONCLUSÃO}

Obteve-se, a partir de solos com histórico de aplicação do fungicida Mancozeb, 11 isolados, compondo assim uma coleção de microrganismos capazes de crescerem em meio sintético, em diferentes concentrações do produto. Essas condições de crescimento caracterizam as bactérias como tolerantes a esse produto em concentrações superiores a encontradas no campo. A coleção de microrganismos decorrentes da realização dessa pesquisa poderá servir para estudos futuros envolvendo a biodegradação de xenobióticos.

\title{
Molecular and phenotypic identification of bacteria from rhizosphere soil with tolerance to Mancozeb fungicide in Manaus, Amazonas State, Brazil
}

\begin{abstract}
The use of fungicides in agriculture has intensified, causing great impact on soil and biota where they are concentrated. The presence of these compounds in the soil has been causing changes in the behavior of microorganisms, which began to acquire strategies to the presence of these products. Mancozeb is a fungicide from the group of carbamates, whose action by contact inactivates the essential enzymes of fungi. The aims of this study were: isolating soil bacteria; characterizing the isolates with biochemical assays and molecular tools; obtaining the isolated growth on minimal medium supplemented with fungicide; establishing a collection of bacteria with bioremediation potential. Bacteria were isolated from isolation techniques in two different culture media: minimal medium and Bushnell Haas medium plus $3.6 \mathrm{gL}^{-1}$ of Mancozeb. The identification was performed by phenotypic characterization, using biochemical assays to determine gender and molecular identification by sequencing the 16 S region with primers 1492R, 513F, which amplify 1,000 base pairs. Eleven bacterial isolates were identified in four families, four genera and 11 species. The Bacillaceae was the most outstanding family, with $81.81 \%$ of the isolates. These tests allowed us to verify the tolerance of bacteria isolated in a higher concentration than used in the field to control pests. The collection of microorganisms from this survey can be used for future studies involving the biodegradation of xenobiotics.
\end{abstract}

Keywords: Fungicide, Industrial; Soil Microbiology; RNA, Ribosomal, 16S; Centesimal Scale; Bacterial Typing Techniques. 


\section{Identificación molecular y fenotípica de bacterias de suelo rizosférico con tolerancia al fungicida Mancozeb, en Manaus, Estado de Amazonas, Brasil}

\section{RESUMEN}

La utilización de fungicidas en la agricultura se ha intensificado, causando gran impacto en los suelos y en la biota en la que se encuentran. La presencia de esos compuestos en el suelo viene causando modificaciones en el comportamiento de los microorganismos, que pasaron a adquirir estrategias de supervivencia a la presencia de esos productos. El Mancozeb es un fungicida del grupo de los carbamatos, cuya acción por contacto desactiva las enzimas esenciales de los hongos. Los objetivos de este trabajo fueron: aislar bacterias de suelo; caracterizar los aislados con ensayos bioquímicos y herramientas moleculares; obtener el crecimiento de los aislados en medio mínimo acrecido del fungicida; establecer una colección de bacterias con potencial de biorremediación. Las bacterias fueron aisladas a partir de técnicas de aislamiento en dos medios de cultivo diferentes: medio mínimo y medio Bushnell Haas acrecidos de 3,6 $\mathrm{gL}^{-1}$ de Mancozeb. Se identificaron por medio de la caracterización fenotípica, utilizando ensayos bioquímicos para determinar el género e identificación molecular por el uso de secuenciación de la región 16S, con los iniciadores 1492R, 513F, los cuales amplifican 1.000 pares de base. Los 11 aislados de bacterias se identificaron en cuatro familias, cuatro géneros y 11 especies. La familia Bacillaceae fue la más representativa, con $81,81 \%$ de los aislados. Esos ensayos permitieron verificar la tolerancia de las bacterias aisladas en concentraciones superiores a las usadas en campo para el control de plagas. La colección de microorganismos resultantes de la realización de esta investigación podrá servir para estudios futuros involucrando la biodegradación de xenobióticos.

Palabras clave: Fungicida Industrial; Microbiología del Suelo; ARN Ribosómico 16S; Técnicas de Tipificación Bacteriana.

\section{REFERÊNCIAS}

1 Marshall CG, Lessard LAD, Park LS, Wright GD. Glycopeptide antibiotic resistance genes in glycopeptide-producing organisms. Antimicrob Agents Chemother. 1998 Sep;42(9):2215-20.

2 Zambolim L, Vale FXR, Monteiro AJA, Costa $\mathrm{H}$. Controle de doenças de plantas: fruteiras. Viçosa: Universidade Federal de Viçosa; 2002.

3 Oliveira Filho FM. Levantamento para diagnóstico da comunidade Nova Esperança: 4 etapa, Jorge Teixeira, município de Manaus. Manaus: IDAM SEPROR; 2009.

4 Juliatti FC. Modo de ação dos fungicidas sobre plantas e fungos. In: Simpósio sobre Relação entre Nutrição Mineral e Incidência de Doença de Plantas [Internet]; 2005 fev 28-mar 1; Piracicaba: POTAFOS; 2005 [citado 2014 jan 10]. Disponível em: http://www.ipni.net/ppiweb/pbrazil.nsf/1 c678d0 ba742019483256e19004af5b8/4d4c7e5503f5a2c 503256fdd004c4a8f/\$FILE/Anais\%20Fernando\%20 Juliatti.pdf.

5 Fawole OB, Aluko ME, Olowonihi TE. Effects of a carbendazim-mancozeb fungicidal mixture on soil microbial populations and some enzyme activities in soil. Agrosearch. 2010;10(1-2):65-74

6 Gaylarde C, Belinasso M, Manfio G. Biorremediação. Biotecnol Cienc Desenvol. 2005 jan-jun;8(34):36-43.
7 Procópio AR. Diversidade da comunidade bacteriana da rizosfera de arroz resistente a propanil e seu potencial biotecnológico [tese]. São Paulo (SP): Universidade de São Paulo; 2007.

8 Bando YS. Taxonomia bacteriana. In: Trabulsi LR, Alterthum F. Microbiologia. 5. ed. São Paulo: Atheneu; 2008. p. 51-5.

9 Vos P, Garrity G, Jones D, Krieg NR, Ludwig W, Rainey FA, et al, editors. Bergey's manual of systematic bacteriology. Vol. 3, The firmicutes. New York: Springer; 2009.

10 Levy CE. Manual de microbiologia clínica para - controle de infecção em serviços de saúde [Internet]. Brasília: Agência Nacional de Vigilância Sanitária; 2004 [citado 2012 mar 17]. Disponível em: http://bvsms.saude.gov.br/bvs/publicacoes/ manual_microbiologia_completo.pdf.

11 Sambrook J, Russel DW. Molecular cloning: a laboratory manual. 3rd. ed. New York: CSHL Press; 2001.

12 Borneman J, Triplet EW. Molecular microbial diversity in soils from eastern Amazonia: evidence for unusual microorganisms and microbial population shifts associated with deforestation. Appl Environ Microbiol. 1997 Jul;63(7):2647-53.

13 Hall TA. BioEdit: a user-friendly biological sequence alignment editor and analysis program for Windows 95/98/NT. Nucl Acids Symp Ser. 1999;(41):95-8. 
14 Schäffer AA, Aravind L, Madden TL, Shavirin S, Spouge JL, Wolf $\mathrm{Yl}$, et al. Improving the accuracy of PSI-BLAST protein database searches with composition-based statistics and other refinements. Nucleic Acids Res. 2001 Jul;29(14):2994-3005.

15 National Committee for Clinical Laboratory Standards. Metodologia dos testes de sensibilidade a agentes antimicrobianos por diluição para bactéria de crescimento aeróbico: norma aprovada - M7-A6. 6. ed. Agência Nacional de Vigilância Sanitária, tradutor. Wayne (PA): NCCLS; 2003. (NCCLS document; vol. 23; no. 2).

16 Ranjard L, Franck P, Nazaret S. Monitoring complex bacterial communities using culture-independent molecular techniques: application to soil environment. Res Microbiol. 2000 Apr;151(3): 16777.

17 King A, Phillips I. The identification of pseudomonas and related bacteria in a clinical laboratory. J Med Microbiol. 1978 May;1 1 (2):165-76.

18 Ahmed I, Yokota A, Yamazoe A, Fujiwara T. Proposal of Lysinibacillus boronitolerans gen. nov. sp. nov., and transfer of Bacillus fusiformis to Lysinibacillus fusiformis comb. nov. and Bacillus sphaericus to Lysinibacillus sphaericus comb. nov. Int J Syst Evol Microbiol. 2007 May;57(P+ 5): $1117-25$.
19 Mandal K, Singh B, Jariyal M, Gupta VK. Microbial degradation of fipronil by Bacillus thuringiensis. Ecotoxicol Environ Saf. 2013 Jul;93:87-92.

20 Andrighetti MS. Biodegradação de glifosato por bactérias isoladas de solos cultivados com macieira com diferentes históricos de aplicação deste herbicida [dissertação]. Porto Alegre (RS): Universidade Federal do Rio Grande do Sul; 2001. 109 p.

21 Sarkar S, Seenisavan S, Asir RPS. Biodegradation of propargite by Pseudomonas putida, isolated from tea rhizosphere. J Hazard Mater. 2010 Feb; 174(1-3):295-8.

22 Singh B, Kaur J, Singh K. Biodegradation of malathion by Brevibacillus sp. strain KB2 and Bacillus cereus strain PU. World J Microbiol Biotechnol. 2012 Mar;28(3): $1133-41$.

23 Batisson I, Crouzet O, Besse-Hoggan P, Sancelme M, Mangot JF, Mallet $C$, et al. Isolation and characterization of mesotrione-degrading Bacillus sp. from soil. Environ Pollut. 2009 Apr;157(4): $1195-201$.

Recebido em / Received / Recibido en: 21/4/2014 Aceito em / Accepted / Aceito en: 26/3/2015 